\title{
Primate-specific spliced PMCHL RNAs are non-protein coding in human and macaque tissues
}

\author{
Sandra Schmieder ${ }^{\dagger 1}$, Fleur Darré-Toulemonde ${ }^{\dagger 1,4}$, Marie-Jeanne Arguel ${ }^{1,2}$, \\ Audrey Delerue-Audegond ${ }^{1,2}$, Richard Christen ${ }^{3}$ and Jean-Louis Nahon*1,2
}

\begin{abstract}
Address: ${ }^{1}$ Université de Nice-Sophia Antipolis, CNRS, Institut de Pharmacologie Moléculaire et Cellulaire, 660 route des lucioles, 06560 Valbonne, France, ${ }^{2}$ Biothèque Primates/Primatech, Centre National de la Recherche Scientifique, Life Science Department, Bordeaux-Valbonne, France, ${ }^{3}$ Université de Nice-Sophia Antipolis, CNRS, Virtual Biology Lab, Parc Valrose, 06108 Nice, France and ${ }^{4}$ Institut de Biologia Evolutiva (UPF-CSIC), CEXS-UPF-PRBB, C/Dr Aiguader, 88, Barcelona 08003, Spain

Email: Sandra Schmieder - schmieder@ipmc.cnrs.fr; Fleur Darré-Toulemonde - fleur.darre@laposte.net; MarieJeanne Arguel - fauvergue@ipmc.cnrs.fr; Audrey Delerue-Audegond - delerue@ipmc.cnrs.fr; Richard Christen - richard.christen@unice.fr; JeanLouis Nahon* - nahon@ipmc.cnrs.fr

* Corresponding author †Equal contributors
\end{abstract}

Published: 9 December 2008

BMC Evolutionary Biology 2008, 8:330 doi:10.1 |86/|47/-2/48-8-330
Received: 8 August 2008

Accepted: 9 December 2008

This article is available from: http://www.biomedcentral.com/I47I-2I48/8/330

(c) 2008 Schmieder et al; licensee BioMed Central Ltd.

This is an Open Access article distributed under the terms of the Creative Commons Attribution License (http://creativecommons.org/licenses/by/2.0), which permits unrestricted use, distribution, and reproduction in any medium, provided the original work is properly cited.

\begin{abstract}
Background: Brain-expressed genes that were created in primate lineage represent obvious candidates to investigate molecular mechanisms that contributed to neural reorganization and emergence of new behavioural functions in Homo sapiens. PMCHLI arose from retroposition of a pro-melanin-concentrating hormone $(P M C H)$ antisense mRNA on the ancestral human chromosome $5 \mathrm{pl} 4$ when platyrrhines and catarrhines diverged. Mutations before divergence of hylobatidae led to creation of new exons and finally PMCHLI duplicated in an ancestor of hominids to generate $P M C H L 2$ at the human chromosome $5 q$ I3. A complex pattern of spliced and unspliced PMCHL RNAs were found in human brain and testis.

Results: Several novel spliced PMCHL transcripts have been characterized in human testis and fetal brain, identifying an additional exon and novel splice sites. Sequencing of PMCHL genes in several non-human primates allowed to carry out phylogenetic analyses revealing that the initial retroposition event took place within an intron of the brain cadherin $(C D H / 2)$ gene, soon after platyrrhine/catarrhine divergence, i.e. 30-35 Mya, and was concomitant with the insertion of an AluSg element. Sequence analysis of the spliced PMCHL transcripts identified only short ORFs of less than $300 \mathrm{bp}$, with low (VMCH-p8 and protein variants) or no evolutionary conservation. Western blot analyses of human and macaque tissues expressing PMCHL RNA failed to reveal any protein corresponding to $\mathrm{VMCH}-\mathrm{p} 8$ and protein variants encoded by spliced transcripts.

Conclusion: Our present results improve our knowledge of the gene structure and the evolutionary history of the primate-specific chimeric $P M C H L$ genes. These genes produce multiple spliced transcripts, bearing short, non-conserved and apparently non-translated ORFs that may function as mRNA-like non-coding RNAs.
\end{abstract}




\section{Background}

There is an ancient [1] but still active debate in the molecular biologist community about the relative contribution of structural genomic modifications [2] that could account for the phenotypic differences observed between primate species, particularly in the emergence of new brain structure and functions $[3,4]$. Very debated results were found when determining the $\mathrm{Ka} / \mathrm{Ks}$ ratio, a tentative indicator of positive Darwinian selection, in the coding region of genes expressed in the mammalian brain [5-7]. However, genome-wide comparative studies of mammalian promoters suggested an accelerated evolution of primate promoters during the last 25 million years [8-10]. Recently, divergence between human and chimpanzee sequences have been re-evaluated to almost 5\%, resulting mainly from indel events [2,11-13] and copy number variants (CNVs) that strongly contributed in shaping primate genomes [14], offering therefore a wide variety of sites at which primate lineage-specific genetic novelty could happen. Indeed, recent segmental duplications are particularly enriched in genes that display expression differences between humans and chimpanzees [15]. In addition, an accelerated rate of contraction or expansion in gene families, including brain-expressed genes, operated in primates when compared with other mammals [16]. On a larger scale, CNVs contributed significantly to diverse expression phenotypes in primates [17] and to emergence of complex or sporadic diseases in humans [18]. To reconcile apparently conflicting data, we previously proposed that, in parallel to single nucleotide mutations that confer alterations in the gene expression patterns or amino acids sequences, genomic rearrangements may have played an important role during primate evolution, providing creation of novel but rare regulatory modules as well as protein coding and/or non-coding genes [19-21]. Indeed, combination of exon shuffling, retrotransposition and gene promoter fusion have led to genes harbouring completely new structures and expression patterns selectively in the primate lineage (reviewed in $[22,23]$ ). These rare events would have been nevertheless particularly important in shaping human genes found expressed in reproductive organs, as exemplified by the chimeric POTE-actin genes [24], or involved in hominoid brain neurotransmission, as exemplified by the GLUD2 gene [25].

The study of primate-specific gene creation and early evolution requires the discovery of genes that have retained characteristic features of their youth [26]. The PMCHL system, which combines the retroposition/exon shuffling and the segmental duplication models, has been one of the first hominoid-specific gene creation model described [19-21,27,28]. We have shown that these genes have been created in the hominoid lineage through i) retroposition at the ancestral chromosome 5p14 locus in catarrhini of an antisense pro-melanin-concentrating hormone (PMCH) gene transcript, ii) local rearrangement leading to a truncated version of the retrogene, iii) sequence remodelling (indel and mutation accumulation that allowed creation of exons) and iv) final duplication at the ancestral 5q13 locus in hominids. Furthermore, processed and unprocessed transcripts were characterized in a human fetal brain library [19] as well as in developing human brain [27]. These mRNAs were found to encode a putative nuclear protein of $8 \mathrm{kD}$, named VMCH-p8, that was only identified using in vitro translation systems or transfected cell models [27]. However, many questions remained unsolved regarding the region and time of insertion of the retrogene, the fine structure of both genes (complete exon/intron structure), their expression patterns (in particular the relative abundance and tissue-specificity of processed transcripts) and their protein coding potential in human cells.

In this paper, we established the structure of PMCHL1/ PMCHL2 genes and demonstrated that alternatively spliced transcripts encompassing exons 1 to 6 are mostly expressed in human testis. We established further the evolutionary history and regional organization of $P M C H L$ genes at both loci on human chromosome 5 and proposed that a single retroposition event followed by point mutations provided novel exonic sequences in transcriptional sense direction. Several short open reading frames (ORFs) were found encoded within the spliced PMCHL RNAs but most of them were not conserved in the primate lineage. This suggests a lack of overt functionality of these ORFs, even though the existence of a small species-specific protein cannot be ruled out. Finally, we attempted to identify proteins generated from PMCHL genes in macaque and human tissues with an antiserum directed against VMCH-p8 and its variants but we failed to detect them. Therefore, spliced transcripts from the primate-specific PMCHL1/PMCHL2 genes would likely represent mRNA-like non-protein coding RNAs (ncRNAs).

\section{Results and discussion \\ I. Structure and distribution of spliced PMCHL transcripts in human brain and testis}

In our previous study [19], we characterized several alternatively spliced transcripts harbouring exons 1 to 5 of the original PMCHL1/PMCHL2 genes. Six transcripts corresponding to PMCHL1 spliced RNA were found in testis and/or fetal brain. Two PMCHL2 spliced RNA were reported only in testis. In order to further precise the exon/intron structure of PMCHL genes and to further investigate the tissue distribution of spliced PMCHL transcripts, we examined the presence of additional RNAs in human testis and cortex Marathon cDNA libraries, as well as in a human fetal prefrontal cortex sample. For this, we performed PCR experiments (Figure 1) using primer pairs designed to amplify (in one or two rounds of PCR) tran- 
A

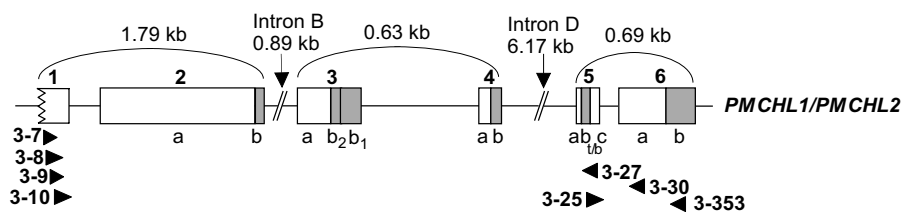

B

Testis Marathon cDNA library
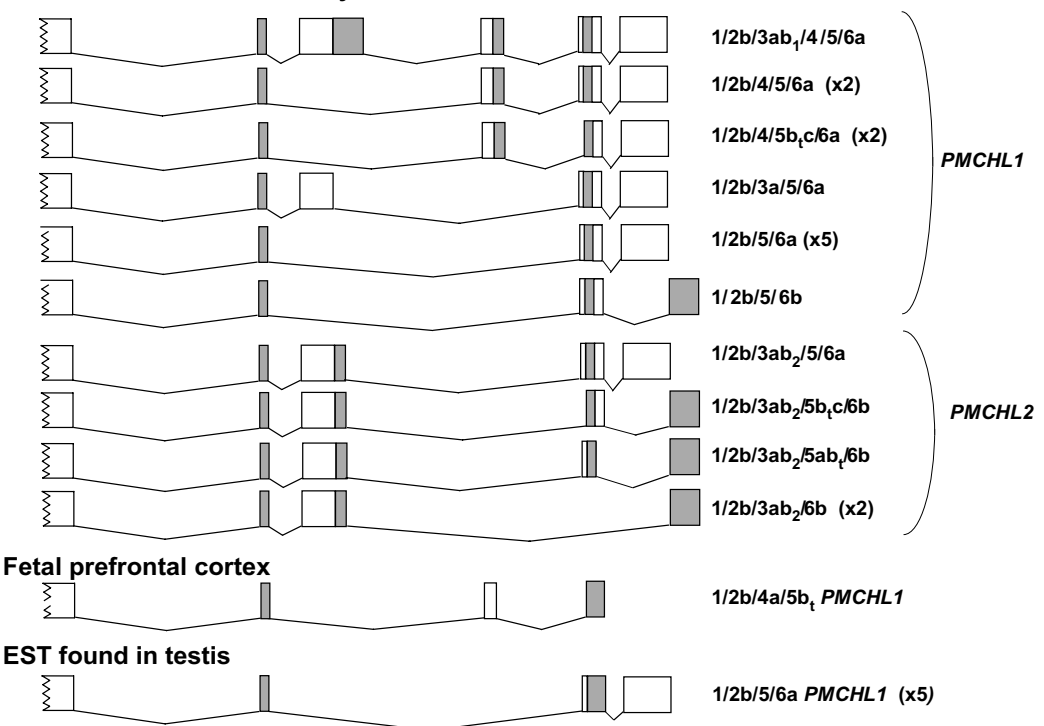

EST found in HT1080 cells

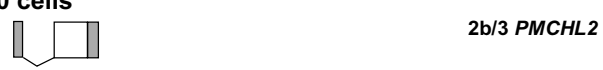

C

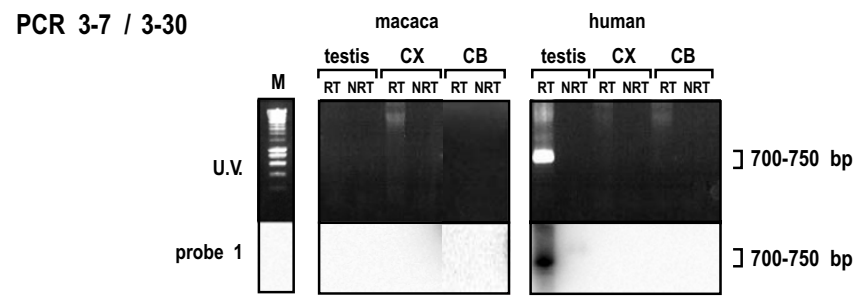

\section{Figure I}

Identification of spliced PMCHL transcripts. (A) PMCHL exon/intron structure as deduced from previous [19] and present transcript sequences. Primer positions are indicated. (B) Identification of alternative spliced transcripts by PCR and sequencing. For human testis, transcripts harbouring exons I and 6a were amplified using primer pair 3-9/3-30, and transcripts harbouring exons I and 6b were amplified using primer pair 3-9/3-353, followed by 3-10/3-353. For human fetal brain, PCR primer pairs were 3-7/3-30, followed by 3-8/3-27. Documented ESTs [GenBank:Al20369l; EMBL:BX09|674; GenBank:AA724728; GenBank:BG 184695] corresponding to spliced transcripts are represented. The number of independent clones for each transcript identified in our previous [19] and present studies are indicated in brackets. The $3 \mathrm{~b}$ splice donor site differs in PMCHLI (named $3 b_{1}$ ) and PMCHL2 (named $3 b_{2}$ ). Two $5 b$ splice acceptor sites (indicated by $t / b$ ), separated by four nucleotides, were identified. GenBank accession numbers of transcripts are: [GenBank:EU92I424, GenBank:EU92I425, GenBank:EU921426, GenBank:EU921427, GenBank:EU921428, GenBank:EU921429, GenBank:EU92I430, GenBank:EU92I431, GenBank:EU921432, GenBank:EU921433, GenBank:EU921434, GenBank:EU92I435, GenBank:EU93838I]. (C) RT-PCR and Southern blot analysis of spliced transcripts in human and macaque adult testis, prefrontal cortex (CX) and cerebellum (CB). Spliced transcripts were detected only in human testis. PCR amplification was with primer pair 3-7/3-30. Molecular weights are indicated. $M$, size markers; RT, reverse transcribed; NRT, non-reverse transcribed. 
scripts encompassing the most distant known exons, previously named exons 1 and 5. Sub-cloning of the PCR products and sequencing of individual clones allowed the discovery of a novel exon, located between exon 2 and former exon 3. It was named exon 3 and previously named exons 3, 4 and 5 are now renamed exons 4, 5 and 6 (Figure 1A, top panel).

We identified six PMCHL1 spliced variants in adult testicular Marathon cDNA library (Figure 1B), two of which [GenBank:EU921424, GenBank:EU921428] had already been identified in the same cDNA library [Gen-

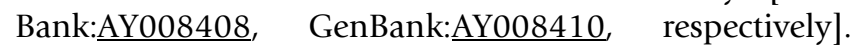
However, transcript [GenBank:EU921424] bears one A to $\mathrm{G}$ mutation within exon 1, resulting in an arginine to glycine mutation in ORF1. Noteworthy, transcript [GenBank:EU921428] corresponds also to two testis ESTs (IMAGE clone 1753807 [GenBank:AI203691; EMBL:BX091674] and IMAGE clone 1326573 [GenBank:AA724728]), and was also found in a human fetal brain Marathon cDNA library in our previous study [19]. This apparently abundant transcript harbours exons 1-2b and $6 a$, like most spliced transcripts in testis which were obtained in a single round of PCR. In contrast, transcripts harbouring exon $6 \mathrm{~b}$ were identified after two rounds of PCR and never contained exon 6a. Transcripts containing exon 2 a were never observed in the present study.

We also identified four novel alternative PMCHL2 splicings in adult testis, which all contained a partial exon 3 $\left(3 b_{2}\right)$ shorter than the original exon $3\left(3 b_{1}\right)$ observed in a PMCHL1 transcript (Figure 1B). Sequence analysis (see Figure 2) revealed that mutations in the PMCHL2 sequence created a novel gene-specific splice donor site $\left(3 \mathrm{~b}_{2}\right)$ which is systematically used in the present PMCHL2 transcripts.

We further identified one novel PMCHL1 splice variant in a fetal prefrontal cortex sample (Figure 1B). This transcript was the only one to harbour an alternative splice donor in exon 4, which was never observed in testis RNAs.

In our previous study [19], we reported two alternative acceptor sites in exon 5b (previously named exon 4b) separated by only four nucleotides and with apparent testisand brain-specificities (indicated by superscript t/b in Figure 1). Our present results show that most testis transcripts use the exon 5a splice acceptor site, and two use the alternative $5 b_{t}$ site. However, the PMCHL1 transcripts identified in fetal brain also use the alternative $5 b_{t}$ site indicating that it could not be considered anymore as a testis-specific splice acceptor site. The alternative $5 b_{b}$ site, previously reported in a fetal brain transcript was not found in our present study.
In contrast to human testis and fetal brain, we could not detect any spliced PMCHL RNA harbouring exons 1 and $6 \mathrm{a}$ in the human adult cortex Marathon cDNA library using the 3-7/3-30 primer pair. This primer pair was further used in RT-PCR experiments combined with Southern blot to determine the tissue distribution of the spliced transcripts in testis, prefrontal cortex and cerebellum in adult human and macaque (Figure 1C). In agreement with our results using the Marathon cDNA libraries, we detected spliced PMCHL RNA harbouring exons 1 and $6 a$ in human adult testis, but not in adult prefrontal cortex and cerebellum. Thus, PMCHL1 transcripts are found in testis and fetal brain and are more abundant than PMCHL2 transcripts that are observed only in testis. In addition, PMCHL2 gene expression was reported in HT1080 cells subjected to RAGE (random activation of gene expression), in which an EST [GenBank:BG184695] encompassing exons $2 \mathrm{a}$ and 3 of PMCHL2 has been identified.

In macaque, no spliced transcripts were identified by Southern blot (Figure 1C) in agreement with our sequence analysis indicating that the macaque PMCHL1 gene lacks the exon 6a acceptor splice site (see below).

Taken together, our findings indicate that PMCHL1 and PMCHL2 genes: i) give rise to a complex pattern of alternative splicings, ii) are subject to distinct tissue-specific expressions and iii) are developmentally regulated (i.e. expressed in fetal but not adult cortex).

The finding that a rather high diversity of spliced transcripts are present in testis is not surprising, because of the permissive chromatin environment present in gonads, allowing high transcriptional activity even from weak tissue-specific promoters [29]. Thus, most retroposons evolve into non-functional pseudogenes that are transcribed only in the testis [30]. However, the abrupt emergence of a new chimeric gene in primates could potentially contribute to reproductive barriers and thus play a role in speciation [31]. In this regard the hominoidspecific oncogene Tre 2 appears expressed only in testis while the two parental genes USP32 and TBC1D3, that fused to generate the Tre 2 gene, are expressed in a broad range of human tissues [32]. In addition, the presence of spliced PMCHL transcripts in fetal brain, is rather suggestive of a functional role during human brain development. This would imply that the retroposon acquired an active promoter and has been subjected to selection pressure. Whether these spliced PMCHL transcripts actually play a functional role in testis and fetal brain is an obvious question, which we further addressed below. 
A

\begin{tabular}{|c|c|}
\hline 5' splice donor site : ${ }_{C}^{\mathrm{A}} \mathrm{A} \mathrm{G} \mathrm{g} \mathrm{t}{ }_{\mathrm{g}}^{\mathrm{a}}$ a g t & c a g G: $3^{\prime}$ splice acceptor site \\
\hline $\begin{array}{r}\text { Exon1 HSA, PPY, PPA, PTR, HLA, MML, MFA, CAE: A C A g t g a g t } \\
\text { HSA MCH :---------- }\end{array}$ & $\begin{array}{l}\text { c a g C : HSA, PPY, PPA, PTR, HLA, MML, MFA, CAE } \\
\text { T: HSA MCH }\end{array}$ \\
\hline \multirow{2}{*}{$\begin{array}{r}\text { Exon2b } \\
\text { HSA, PPY, PPA, PTR, MML, MFA, CAE : C A A g t a a g t } \\
\text { HLA: }\end{array}$} & c a g T: HSA, PPY, PPA, PTR, HLA, MML, MFA, CAE \\
\hline & c a g A : HSA, PTR, PPA, HLA, MML, MFA, CAE \\
\hline $\begin{array}{r}\text { HSA, PPY, PPA, PTR L2, CAE : T } \mathrm{g} \mathrm{T} \mathrm{g} \mathrm{g} \mathrm{g} \text { g } \mathrm{a} \\
\text { PTRL1, CAE, MML, MFA: }\end{array}$ & t a g G: HSA, PTR, PPA, HLA, MML, MFA, CAE \\
\hline HSA L2, PTR L2: G T G g t a a a & c a g T: HSA, PTR, PPA, HLA, CHA, MML, MFA CAE, SOE, CCA, CAP \\
\hline 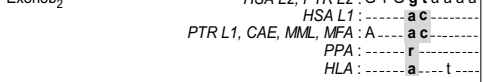 & $\begin{array}{l}\text { c a g A : HSA, PTR, PPA, HLA, CHA, MML, MFA, CAE, CAP Exon5b } \\
-c-G: C C A\end{array}$ \\
\hline 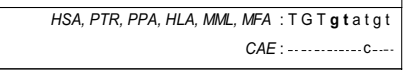 & $\begin{array}{l}\text { t a g T: HSA, PTR, PPA, HLA, CHA, CAE, CAP, SOE, CCA Exon5b } \\
\text { a } \\
\text { :-.: MML, MFA }\end{array}$ \\
\hline \multirow{2}{*}{ 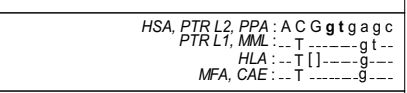 } & 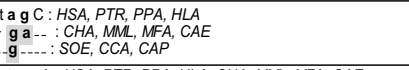 \\
\hline & $\begin{array}{l}\text { t a g A : HSA, PTR, PPA, HLA, CHA, MML, MFA, CAE } \\
\text {-g.-.-: SOE, CCA, CAP }\end{array}$ \\
\hline HSA, PTR, PPA, HLA, MML, MFA, CAE: T C A g $\mathrm{t} \mathrm{t}$ a a $\mathrm{g}$ & \\
\hline 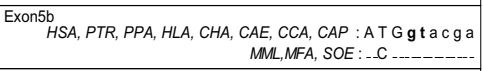 & \\
\hline 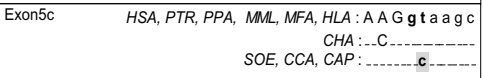 & \\
\hline
\end{tabular}

B

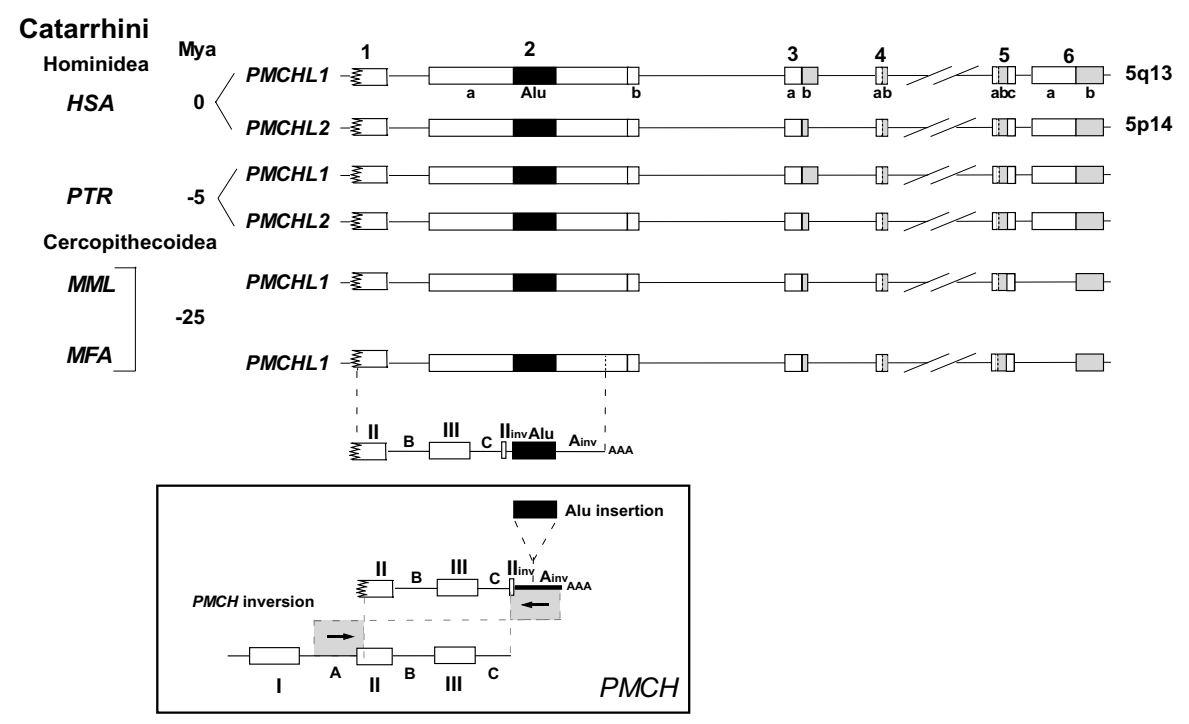

\section{Figure 2}

Phylogenetic analysis of the intron-exon boundaries of the PMCHL genes.(A) Comparative sequence analysis of PMCHL splice donor and acceptor sites. Exonic nucleotides are in uppercase letters, and intronic nucleotides are in lowercase. Consensus splice donor and acceptor sequences are indicated. The most invariant dinucleotides gt and ag are in bold characters. Sequence differences in these dinucleotides are boxed in grey. Dashes indicate identity with the sequence in the first row. Brackets indicate a gap. GenBank accession numbers and positions in http://www.ensembl.org are as follows: PMCH HSA [GenBank:NM002674], PMCHLI HSA chr 5p I4, 22I782 I8-22I 8842I, PMCHL2 HSA chr 5q I3, 70707368-707I7576, PMCHLI PTR chr 5, 93832488-93866206, PMCHL2 PTR chr 5, 44567880-4460047I, PMCHL PPA [GenBank:EF043264], PMCHL PPY [GenBank:AY0084I5, GenBank:AY008422, GenBank:AY008419], PMCHL HLA [GenBank:EF043266], PMCHL CAE [GenBank:EF043268], PMCHL MML chr 6, 22205I53-222I5832, PMCHL MFA [GenBank:EF043267], PMCHL CHA [GenBank:AY008430], PMCHL SOE [GenBank:EF043262], PMCHL CAP [GenBank:EF043263], PMCHL CCA [GenBank:AY00843I]. (B) Schematic representation of the PMCHLI and PMCHL2 exon/intron structures in Homo sapiens (HSA), Pan troglodytes (PTR), Macaca mulatta (MML) and Macaca fascicularis (MFA). The position of the retroposed sequence derived from the antisense strand of the PMCH locus is indicated and detailed correspondence between the sequences is given (inset). Times of divergence are indicated (Mya). 


\section{Evolutionary history of the PMCHL genes} Retroposition-driven creation of PMCHLI gene occurred 30-35 Mya in primate lineage

To gain further insights into the evolutionary history of the $P M C H L$ gene family, we extended our previously initiated sequence analysis of $P M C H L$ and $P M C H$ genes. For this, genomic DNAs were PCR amplified with the $P M C H L$ - or $P M C H$-specific primer pairs indicated in Table 1 and the PCR products were sequenced. Novel sequences were submitted to GenBank under the following accession numbers. For PMCHL1: [GenBank:EF043262] (SOE), [GenBank:EF043263] (CAP), [GenBank:EF043264] (PPA), [GenBank:EF043265] (PTR), [GenBank:EF043266] (HLA), [GenBank:EF043267] (MFA), [GenBank:EF043268] (CAE). For PMCH: [GenBank:EU916242] (TSY), [GenBank:EU916243] (MFA), [GenBank:EU916244] (CAE), [GenBank:EU916245] (SOE), [GenBank:EU916246] (CCA), [GenBank:EU916247] (PPA), [GenBank:EU916248] (PTR), [GenBank:EU916249] (HLA)].

We first carried out the phylogenetic analysis of the exon/ intron boundaries of the PMCHL genes (Figure 2A, B). Consensus gt/ag splice donor and acceptor sites are present in all species bearing the retroposon, i.e. all catarrhines of this study, with the exception of the splice acceptor site of exon $6 \mathrm{a}$ which is present only in hominoids. Moreover, the exon $5 \mathrm{c}$ donor site and the $6 \mathrm{a}$ and $6 \mathrm{~b}$ splice acceptor sites were not consensual in the platyrrhines analysed here, i. e. before the retroposition event, suggesting that canonical splicing could not occur in this ancestral region before the arrival of the retroposed sequence. Our sequence analysis showed that these splice sites were created de novo through single nucleotide mutations. Thus, the splicing between exons 5 and 6 corresponds to de novo exonisation and not to an Alu-driven exonisation mechanism [33], exon 6 being absent in platyrrhines and then conserved through selection pressure. In contrast, splice sites of exons 3 and 4 pre-dated the retroposition event, indicating that a fusion of the $\mathrm{PMCH}$-derived exons with pre-existing exons is likely to have occurred. Whether these exons were expressed before the retroposition remains to be determined, but no expressed sequence tag corresponding to exons 3 and 4 alone could be identified in mammalian EST databases. Furthermore, chimeric transcripts formed by transcription of two consecutive genes into a single RNA can occur quite frequently in human cells [34]. A similar mechanism may be involved in the production of fused transcripts encompassing either exon 3 or 4 of PMCHL1/PMCHL2 genes. However, further characterization of putative promoters inside the PMCHL genes needs to be done before involving such RNA domain accretion process on regulation of these genes.
A nucleotidic phylogenetic analysis (Figure 3) was performed to date more precisely the retroposition event. As $P M C H L$ genes encompass part of the $P M C H$ gene sequence (sense and antisense), it was possible to align primate sequences of these specific parts of the PMCHL1 and $\mathrm{PMCH}$ genes. The phylogenetic analysis was performed using the parsimony, maximum-likelihood and neighbour-joining methods and with the rat and mouse $\mathrm{PMCH}$ sequences as outgroups (Figure $3 \mathrm{~A}$ ). All phylogenetic methods led to congruent data, with high bootstrap values with the neighbour joining method. The tree showed an apparent aberration relative to our present knowledge concerning the relationship between species and the creation of the PMCHL1 gene (circled in Figure $3 \mathrm{~A})$. We expected the PMCH sequences of Cebus capucinus and Saguinus oedipus to be grouped with the $\mathrm{PMCH}$ sequence of Tarsius syrichta rather than with the PMCHL sequences. However, a noteworthy low bootstrap value $(34 \%)$ was found for this branching. The position of the PMCHL sequences as well as the uncertainty for positioning the Cebus capucinus and Saguinus oedipus PMCH sequences suggest that the retroposition event leading to the PMCHL1 gene occurred very shortly (likely within 5 million years) after the split of platyrrhini/cathyrrhini, i.e. 30-35 Mya $[35,36]$.

When focusing on the PMCHL genes, in the regions encompassing exons 1-2b (Figure 3B) and exons 5-6 (Figure $3 \mathrm{C}$ ) the nucleotidic phylogenetic trees fully correspond to accepted species trees, indicating that no particular and global (since here the entire gene sequences were used) evolutionary event interfered. However, we observed a difference in the Pan troglodytes/Pan paniscus/ Homo sapiens positioning between the two phylogenetic trees. This simply corresponds to an inherent irresolution in the hominidae speciation, which could be inferred (or not) from a complex speciation with interbreeding before final separation of chimpanzees, gorillas and humans [3739]. All three species should probably be grouped under the Pan or Homo clade as previously suggested $[35,40,41]$.

We previously reported the presence of a complete Alu-Sq sequence element within PMCHL exon 2 [27], but the insertion event into PMCHL1 could not be dated precisely. It is worth noting that this sequence appears to be an AluSg, and not an Alu Sq element. Our present sequence analysis reveals that all primate species carrying the PMCHL1 exon 2 harbour the AluSg sequence (Figure $2 \mathrm{~B})$. Thus, the insertion was likely concomitant to the retroposition, occurring after the divergence of Cebus species (C. apella and C. capucinus), and before the divergence of the cercopithecoids, approximately between 30-35 Mya. 
Table I: Sequences of oligonucleotides used for PCR

\begin{tabular}{|c|c|c|c|c|c|}
\hline forward primer & sequence & reverse primer & sequence & $T^{\circ}$ & gene \\
\hline \multicolumn{6}{|l|}{ Sequencing } \\
\hline $\mathrm{I}-2$ & CTCAAGGTATTTTACTTTCAGCATCC & $1-3$ & TGCAGAATTTTCACAAAGTTTAATGCAC & $56^{\circ} \mathrm{C}$ & $\mathrm{PMCH}$ \\
\hline $3-4$ & GGCCATAGGGTGGTTTGG & $3-19$ & TGAGTAGATAAAAGGACTGACTT & $56^{\circ} \mathrm{C}$ & PMCHL \\
\hline $3-18$ & AAGTCAGTCCTTTTATCTACTCA & $3-22$ & TAACCTTGCTTTCTTCCTTTCTATA & $57^{\circ} \mathrm{C}$ & PMCHL \\
\hline $3-15$ & GCGTCAGTGTCCTAATGCAT & $3-68$ & GAATTTCTGAGCTGTGTTGTGC & $58^{\circ} \mathrm{C}$ & PMCHL \\
\hline $3-18$ & AAGTCAGTCCTTTTATCTACTCA & $3-27$ & TGATAACGTGAAATCGTACCAT & $54^{\circ} \mathrm{C}$ & PMCHL \\
\hline $3-20$ & ACTCCACGTCAAGACAGTTGCA & $3-30$ & GATGGAGGTAAACCAAGGAGG & $60^{\circ} \mathrm{C}$ & PMCHL \\
\hline $3-72$ & TTCTGGTTTTCACAGTAACTGATCT & $3-142$ & GGGAAATCAGTGAGTGGAGTAGGAA & $58^{\circ} \mathrm{C}$ & PMCHL \\
\hline $3-110$ & GCTGAAATCCTTCCTCAAGA & $3-33$ & AGCTGATATCCTAGAAGTAG & $53^{\circ} \mathrm{C}$ & PMCHL \\
\hline \multicolumn{6}{|l|}{$\underline{P C R}$} \\
\hline $3-9$ & CTGAGAATGGGGTTCAGGATAC & $3-30$ & GATGGAGGTAAACCAAGGAGG & $58^{\circ} \mathrm{C}$ & PMCHL \\
\hline $3-9$ & CTGAGAATGGGGTTCAGGATAC & $3-353$ & TTTAACAATTGAACACATGTAATCATT & $53^{\circ} \mathrm{C}$ & PMCHL \\
\hline $3-10$ & TGGGGATGAAGAAAACTCAGCTAA & $3-353$ & TTTAACAATTGAACACATGTAATCATT & $53^{\circ} \mathrm{C}$ & PMCHL \\
\hline $3-7$ & CAATGGGATTATGCTGTCACAA & $3-30$ & GATGGAGGTAAACCAAGGAGG & $58^{\circ} \mathrm{C}$ & PMCHL \\
\hline $3-8$ & AACATAATTTCTTAAATCATGG & $3-27$ & TGATAACGTGAAATCGTACCAT & $56^{\circ} \mathrm{C}$ & PMCHL \\
\hline \multicolumn{6}{|l|}{ Probe 1} \\
\hline $3-25$ & TGAGATGTAAAGAGACCACCTT & $3-30$ & GATGGAGGTAAACCAAGGAGG & $58^{\circ} \mathrm{C}$ & PMCHL \\
\hline
\end{tabular}

Annealing temperature $\left(\mathrm{T}^{\circ}\right)$ that was used for $\mathrm{PCR}$ and gene-specificity are indicated for each oligonucleotide pair.

A $92 \mathrm{~kb}$ element encompassing PMCHLI and adjacent intronicl exonic sequence of CDHI 2 on 5 p 14 duplicated to create PMCHL2 on $5 q 13$ at the time of hominid divergence

We previously proposed [19] that PMCHL2 was created from a duplication of a large, but undefined in size, genomic DNA fragment comprising PMCHL1, "jumping" from ancestral hominid chromosome 5p14 to 5q13. Here, we precisely determined the limits of the duplicon by similarity using a BLAST search [42]. It appeared that a fragment of $92 \mathrm{~kb}$, encompassing $17 \mathrm{~kb}$ upstream and 65 $\mathrm{kb}$ downstream of the $10 \mathrm{~kb}$ of PMCHL1 was duplicated (Figure 4). This $92 \mathrm{~kb}$ duplicon corresponds to a large part $(88 \mathrm{~kb})$ of the 5 ' portion of intron 4 of the CDH12 gene encoding brain cadherin (as defined in http:// www.ensembl.org), as well as CDH12 exon 4 and the last $4 \mathrm{~kb}$ of its intron 3 . No other exons (found elsewhere in the genome) than those derived from the $\mathrm{PMCH}$ gene were found in the duplicon. The percentages of identity between the $5 \mathrm{p}$ and $5 \mathrm{q}$ elements were equivalent all along the duplicon (i.e. in the PMCHL genes, and in the 5 ' and 3 ' flanking regions), and are close to $98 \%$, in agreement with a very recent duplication event.

We have therefore precisely mapped the limits of the PMCHL1/PMCHL2 duplicon. A question concerning the creation of novel genes, particularly in the case of segmental duplication, is relative to the acceptor sites. Which kind of sequences allows invasion by foreign sequences? Which kind of sequences can we find at the segmental duplication boundaries? No clear boundaries specificities are described for segmental duplication except for a significant enrichment in short interspersed elements (SINEs) such as young Alu Y and Alu S sequences and other repeats similar to these involved in Ig heavy chain recombination in pericentromeric and interstitial segmental duplications $[2,13,43]$. Alu mediated DNA duplications have exceptionally been reported in eukaryotes [44]. These duplications appeared however to affect mainly hyperrecombinogenic chromosomal regions, and particularly for secondary duplications [43]. Long interspersed elements (LINEs) like Line 1 elements were also directly (i.e. not only favouring Alu sequences duplication) implicated in exon recombination and have been proposed to mediate exon shuffling [22], but none of the previously described human chimeric genes [45] harbour this kind of element at its boundaries. In the case of PMCHL1/L2, no particular SINEs or LINEs sequences could be found at the boundaries, neither at the first insertion site of the $\mathrm{PMCH}$ antisense retroposon (in an intron of the Brain Cadherin (CDH12) gene at the 5p14 locus), nor at the 5q13 locus when creating PMCHL2. Recently, a duplication-driven model for DNA transposition has been put forth by Eichler's group [46] suggesting that the probability for a DNA element to be duplicated correlated with the degree of proximity to so-called core duplicons. In this context, a core duplicon named $\mathrm{Glu}^{5-10}$ and corresponding to a truncated version of the GUSB gene, has been found in close vicinity to PMCHL1 and PMCHL2 genes on 5p14 and $5 q 13$ respectively [20]. Whether the proximity with this duplicon was determinant for emergence of the PMCHL2 gene remains at this stage a matter of speculation but the timing of both $\mathrm{Glu}^{5-10}$ duplicon expansion and intrachromosomal duplication of PMCHL1 in primates fits very well. These duplication events are also con- 

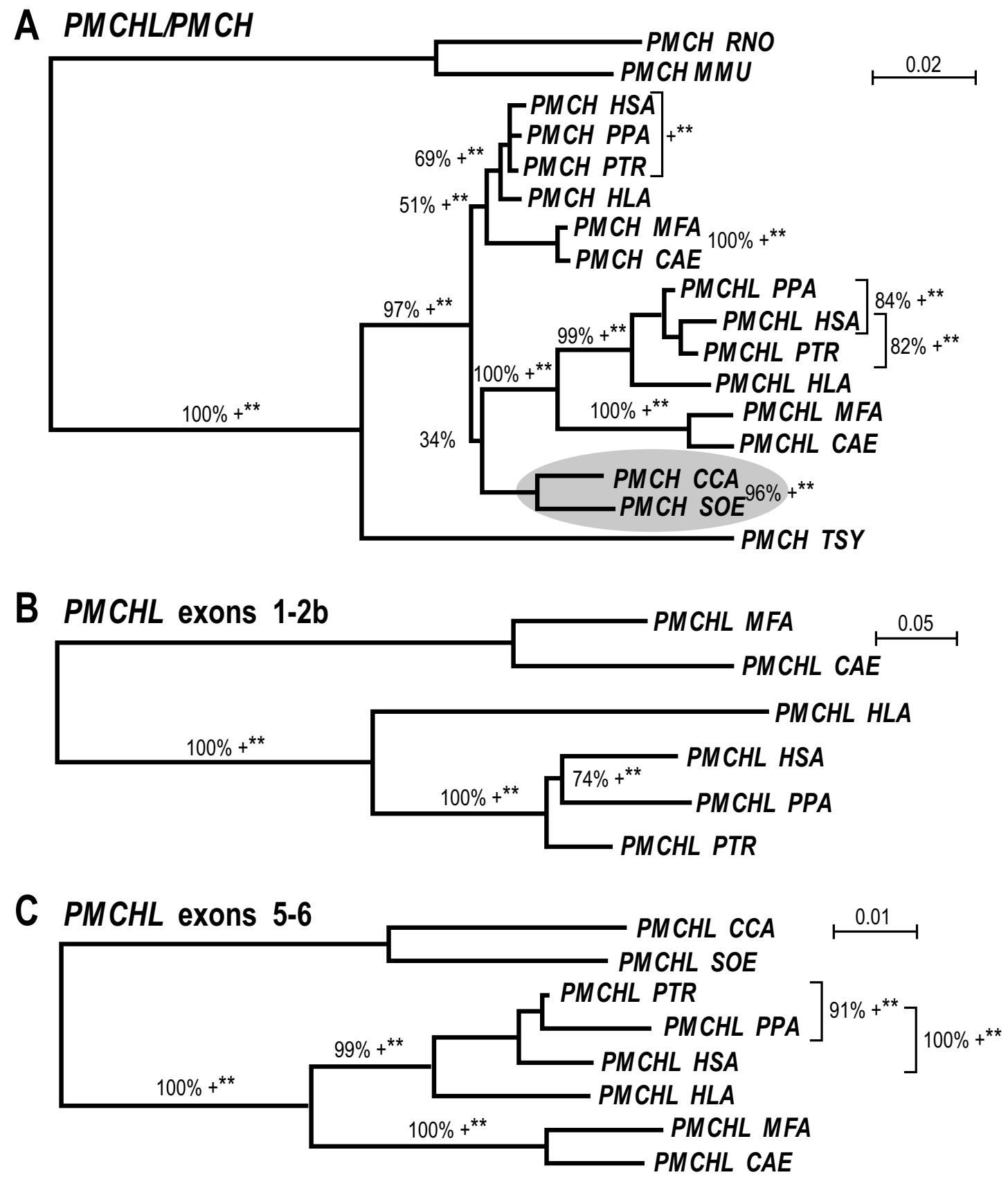

Figure 3

Phylogenetic analyses of the PMCH and PMCHL genes. Phylogenetic analyses of $(\mathrm{A})$ the alignable $P M C H$ and $P M C H L$ sequences, of $(B)$ the region encompassing exon I to exon $2 b$ of $P M C H L$, and of $(C)$ the region encompassing exon 5 to exon 6 of PMCHL. All three unrooted trees were obtained using a neighbour-joining (NJ) method. Branches also found by maximum likelihood (G option) and parsimony are indicated with ** $(\mathrm{P}<0.0 \mathrm{I})$ and + , respectively. Grey oval indicates unresolved localization of the platyrrhine PMCH branch. Mus musculus (MMU) and Rattus norvegicus (RNO) are used as outgroups in (A). GenBank accession numbers and positions in http://www.ensembl.org are as indicated in Figure 2, and the following: PMCH PPA [GenBank:EU916247], PMCH PTR [GenBank:EU9I6248], PMCH HLA [GenBank:EU916249], PMCH MFA [GenBank:EU9I6243], PMCH CAE [GenBank:EU916244], PMCH CCA [GenBank:EU916246], PMCH SOE [GenBank:EU9|6245], PMCH TSY [GenBank:EU916242], PMCH RNO [GenBank:NM0 12625], PMCH MMU [GenBank:NT039500], PMCHLI HSA [GenBank:AY0283 I8, GenBank: AY0283 I9], PMCHL2 HSA [GenBank:AY028320, GenBank:AY02832I], PMCHLI PTR [GenBank:EF043265]. 
gruent with the global surge in intrachromosomal duplications at the time of hominid divergence, as previously predicted [21] and experimentally proven [47].

\section{Analysis of the protein coding potential of PMCHL transcripts}

We next addressed the protein coding potential of the spliced PMCHL RNAs. We examined the sequences of all $P M C H L$ transcripts reported in the present and in our previous study [19] to identify ORFs longer than $100 \mathrm{bp}$. Ten short ORFs of less than 300 bp were found. PMCHL transcripts harbouring exons 5-6a or 5-6b present all together seven ORFs that are 120 to 198 bp in length (Figure 5), i.e. they would encode proteins of 40 to 66 amino acids. ORFs of less than 300 bp (i.e. 100 amino acids) are often assumed not to be translated. However, many well known functional proteins of less than 100 amino acids in length have been reported, including the small inducible cytokine families CCL and CXCL [48], and the xenobiotic defensin and defensin-related cryptidin factors [49]. Furthermore, a recent study has shown that among the 31,035 predicted proteins encoded by the 102,801 FANTOM mouse full-length cDNA sequences, $12 \%$ of the proteins (i.e. 1,683 proteins) are less than 100 amino acids in length [50]. This suggests that there might be up to 4 times more small proteins than the 424 entries present for Mus musculus to date in the SwissProt protein database (release 56). Interestingly, most of the small proteins with known function are evolutionarily conserved [48] or present conserved sequence motifs [49]. Notably, a recent report [51] indicates that ORFs $<300 \mathrm{bp}$ in length, that are not evolutionarily conserved, are unlikely to be translated into functional proteins. Given that the PMCHL ORFs present on exons 5-6a and 5-6b are not conserved among Homo sapiens, Pan troglodytes and Pongo pygmaeus, due to frameshift-causing insertions/deletions (Figure 5), we propose that these ORFs are most likely non-functional.

The longest ORF identified on PMCHL transcripts is 294 bp (98 amino acids) long and locates within the Alu sequence in exon $2 \mathrm{a}$. Four transcripts harbouring exon $2 \mathrm{a}$ were identified in testis in our previous study [19]. However, the corresponding putative protein is not conserved due to a single nucleotide insertion in the human PMCHL1 sequence causing a frameshift in the middle of the ORF. Therefore, this ORF is also spurious according to the criteria of Clamp and colleagues [51].

PMCHL transcripts encompassing exons $1-2 \mathrm{a}$ and $1-2 \mathrm{~b}$ harbour two ORFs, named ORF1a and ORF1b, respectively (Figure 6A, B, C). Even though these ORFs are also less than $300 \mathrm{bp}$ in length, they present the same lengths in Homo sapiens, Pan troglodytes and Pongo pygmaeus, and share $>90 \%$ sequence identity. In Macaca fascicularis, the ORF is shortened and runs only on exon 1 due to the presence of an early stop cordon. These ORFs are of particular

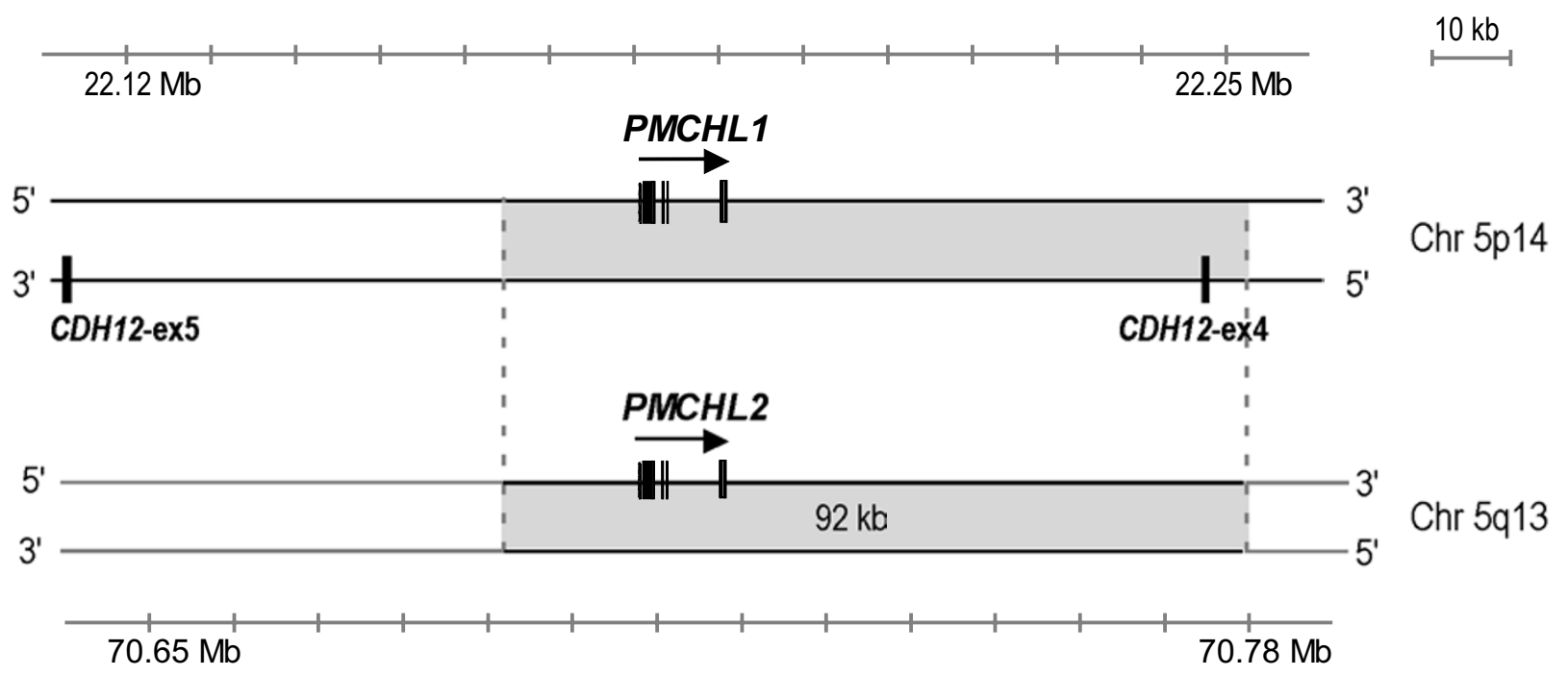

\section{Figure 4}

Schematic map of PMCHL gene positions at human chromosome 5 p 14 and 5 q 13 loci. The six exons of PMCHLI locate within $10 \mathrm{~kb}$ on chromosome $5 \mathrm{pl}$, on the opposite strand of CDHI 2 intron 4. PMCHL2 arose by duplication of a $92 \mathrm{~kb}$ fragment (in grey) encompassing PMCHLI onto chromosome 5ql3. Positions according to http://www.ensembl.org nomenclature are indicated. 
interest because they share a large part of sequence identity with ORF1 present on unspliced PMCHL RNA, and with the pro-MCH precursor because it mainly locates in exon 1, i.e. in the region derived from exon 2 of the ancestor $\mathrm{PMCH}$ gene. The putative $8 \mathrm{kD}$ protein corresponding to ORF1, previously named VMCH-p8, presents a putative nuclear localisation signal (NLS) at the N-terminus (KPKKK, shaded in grey in Figure 6B), and is among the longest ORFs, encoding 72 amino acids (Figure 6A, B, C). In a previous study [27], we examined the protein coding potential of ORF1 carrying out in vitro translation experiments and COS-7 cell transfections with the Flag epitopetagged ORF1. The results indicated a weak protein-coding potential, depending on particular plasmid constructions, providing mRNA stabilising elements and enhanced promoter activity [27]. In the present study, we used a VMCHp8 antiserum directed against the thirteen $\mathrm{N}$-terminal VMCH-p8 amino acids, comprising the putative NLS (see Figure 6B). This allows the determination of the expression of ORF1, as well as the ORF1a and ORF1b variants (sharing the N-terminal epitope). The reactivity of the $\mathrm{VMCH}-\mathrm{p} 8$ antiserum was demonstrated in Western blot experiments using a recombinant GST-VMCH-p8 protein produced in bacteria. $\mathrm{VMCH}-\mathrm{p} 8$ antiserum recognized the GST-VMCH-p8 protein, migrating at about $34 \mathrm{kD}$, whereas the preimmune serum did not (Figure 6D). Next, we used the VMCH-p8 antiserum to examine expression of ORF1 and its variants in human and macaque tissues (Figure 6E). We tested human adult testis, hippocampus and prefrontal cortex extracts from a new-born and a foetus, as well as four Macaca fascicularis cerebral areas (supplementary motor area, cerebellum, prefrontal cortex and visual area). These tissues and cerebral areas were chosen for the presence of ORF1-bearing PMCHL transcripts in RT-PCR experiments ([27,28]; our unpublished data). In our Western blot experiments, no signal could be detected in all human and macaque tissues tested, at the expected size of $8-9 \mathrm{kD}$ for the putative VMCH-p 8 protein and its variants. This strongly suggests that these putative proteins are not translated in vivo in the human and macaque tissues that we tested. We further carried out Western blot and immunoprecipitation experiments on HEK293 cells transfected with PMCHL1/2 sequences bearing ORF1 to detect low levels of VMCH-p8 protein. Even though high levels of ORF1-bearing PMCHL1/2 transcripts were detected by RT-PCR, no signal corresponding to the VMCH-p8 protein could be detected (data not shown). One explanation for the lack of protein detection, that we cannot exclude, is a very low protein expression level below our detection threshold. Also, for the putative Macaque protein, we further cannot exclude an altered epitope-recognition of the antibody due to a lysine to glutamic acid mutation within the epitope. Assuming that the failure to detect the VMCH-p8 protein or its variants is not due to these technical limitations, the lack of transla- tion of ORF1 like-bearing mRNAs could reside in the moderate consensus with the optimal sequence for translation initiation described by Kozak [52]. Actually, only the consensual adenine at position -3 is present.

What might be the role(s) of the large variety of spliced $P M C H L$ mRNAs in human testis and fetal brain? It is tempting to propose that these PMCHL transcripts work mainly as an mRNA-like non-protein coding RNA (ncRNA). Since the realization that $98 \%$ of the transcriptional output in mammals consists of ncRNAs, the enthusiasm for this class of RNAs has grown tremendously [53$55]$ and has been granted its own NONCODE database [56]. Numerous classes of ncRNAs have been reported, most of which are small ncRNAs (including miRNAs, siRNAs and snoRNAs), but also long ncRNAs (ranging from 1 to more than $100 \mathrm{~kb}$ ) such as Xist and the antisense Tsix transcripts involved in $x$ inactivation in mammals $[57,58]$, or the Air RNA that appears to be responsible for imprinted repression of nearby genes (including $I g f 2 r$ gene) through an antisense-mediated mechanism [59]. Several mRNA-like ncRNAs that are transcribed by RNA polymerase II, spliced and polyadenylated have also been reported [60-62], including in human [63,64]. Interestingly, many small ncRNAs are located in introns of coding or non-coding mRNAs [54,65]. The functional roles of ncRNA are diverse, corresponding mainly to adaptor functions targeting nucleic acids to various enzymatic complexes (involved in RNA processing, splicing, transcription...) and gene expression regulation/silencing (involved in virtually all cellular functions).

Do the PMCHL transcripts host small ncRNAs in their introns, and/or do the PMCHL transcripts control the expression of neighbouring genes in cis (an obvious candidate is the CDH12 gene) or in trans through RNA-RNA duplexes (obvious candidates are the $P M C H$ and Antisense RNA Overlapping MCH (AROM) genes)? We are now addressing these intriguing questions.

\section{Conclusion}

We provide here new data concerning spliced PMCHL transcripts, further precising the PMCHL gene structure. Sequencing data of the PMCHL genes in several nonhuman primates offered a substantial improvement of the creation model proposed previously [19]. In particular, we proposed that the initial retroposition occurred within an intron of the $\mathrm{CDH} 12$ gene soon after platyrrhine/catarrhine divergence and was concomitant with the insertion of an Alu Sg element. Our sequence analysis further points to the presence of short ORFs that present little or no evolutionary conservation, suggesting that spliced $P M C H L$ transcripts are non-protein coding RNAs. This proposal is further supported by our expression analysis of the most 


\section{Homo sapiens}

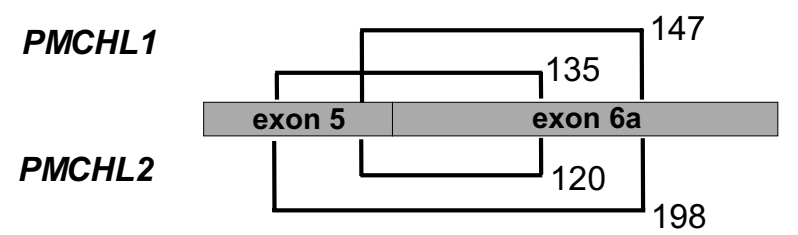

\section{Pan troglodytes}

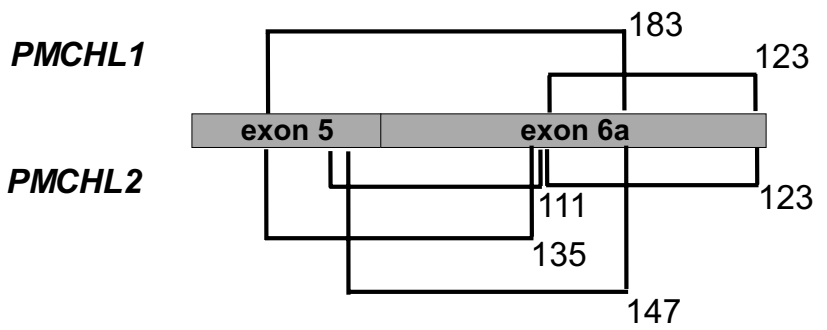

\section{Pongo pygmaeus}

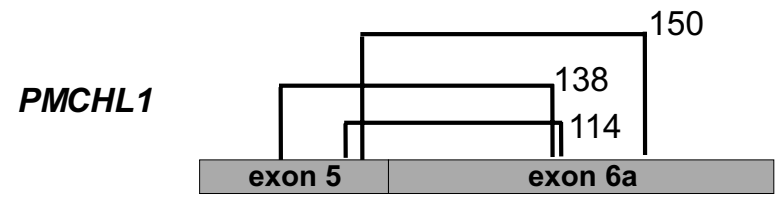

PMCHL1

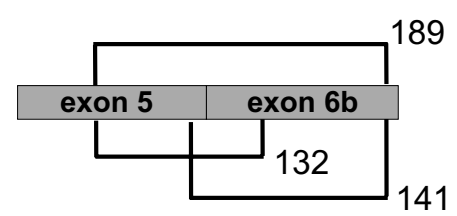

PMCHL1

PMCHL2

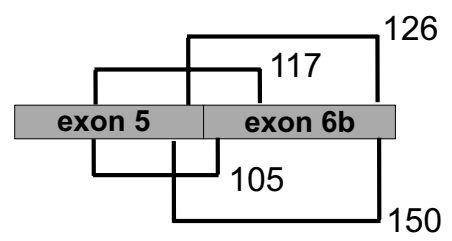

PMCHL1

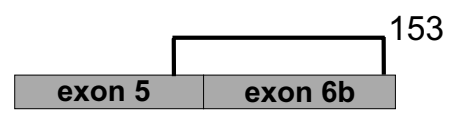

\section{Figure 5}

Mapping of exon 5-6a and exon 5-6b ORFs. Schematic representations of ORFs found on human PMCHLI and PMCHL2 transcripts harbouring exons 5-6a or 5-6b, and on the corresponding putative transcripts in Pan troglodytes and in Pongo pygmaeus. ORFs $>100$ bp are represented by brackets at their relative positions. ORFs are not at scale due to sequence insertions/deletions, but ORF lengths (in base pairs) are indicated.

relevant PMCHL ORFs in human and macaque tissues, which failed to detect any corresponding protein.

\section{Methods}

\section{Tissues}

Human prefrontal cortex and cerebellum from adults were provided by the National Neurological Research Specimen Bank (Los Angeles, CA, USA) and by the GIE Neuro-CEB (Hôpital de la Pitié-Salpétrière, Paris, France), which collect tissues with the full authorization of the respective local ethical committees. Human adult testis RNA was purchased from BioChain/Cliniscience (France). Dr. A. Coquerel (CHU Rouen, France) provided human prefrontal cortex and hippocampus tissues from a newborn. Dr. D. Jordan (Faculté de médecine, Lyon, France) provided human prefrontal cortex and hippocampus tissues from a foetus. Collection of human new-born and foetal tissues was according to the french legislation of parental consent and with the approval of local ethical committees. Human adult testis total proteins were purchased from BioChain/Cliniscience (France). Testis, prefrontal cortex, cerebellum, visual area, and supplementary motor area samples from three adult macaques (Macaca fascicularis) were obtained from Dr. E. Bezard at the Biothèque Primate/Primatech (CNRS, Bordeaux, France), where tissue collection is carried out in agreement with the European Communities Council Directive of November 24, 1986 (86/609/EEC).

\section{Genomic DNAs}

Genomic DNAs were collected from Cebus capucinus (gift from B. Dutrillaux, cytogénétique moléculaire et oncologie, CNRS, Institut Curie, Paris, France), Tarsius syrichta, Saguinus oedipus, Cebus apella, Chlorocebus aethiops, Hylobates lar, Pan paniscus and Pan troglodytes (gift from Dr P. Dijan, CEREMOD, Meudon, France) and were already 
A

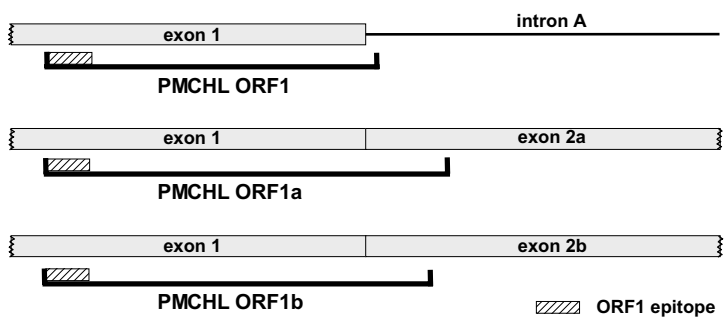

B

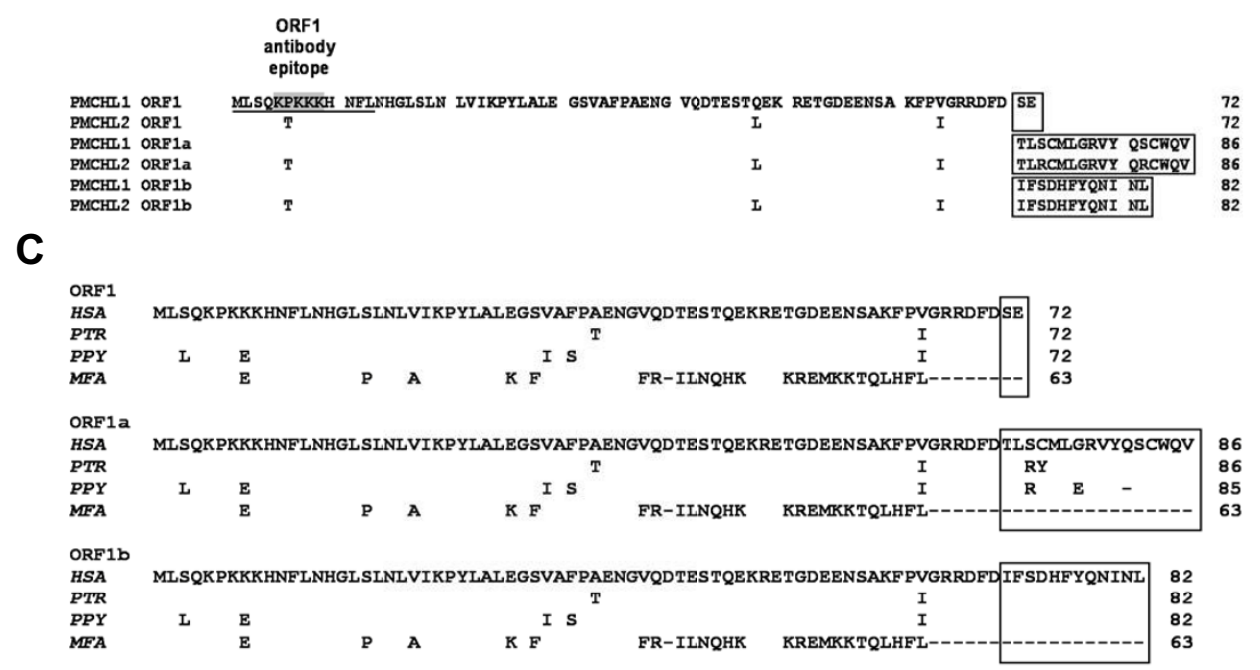

D

$\mathbf{E}$

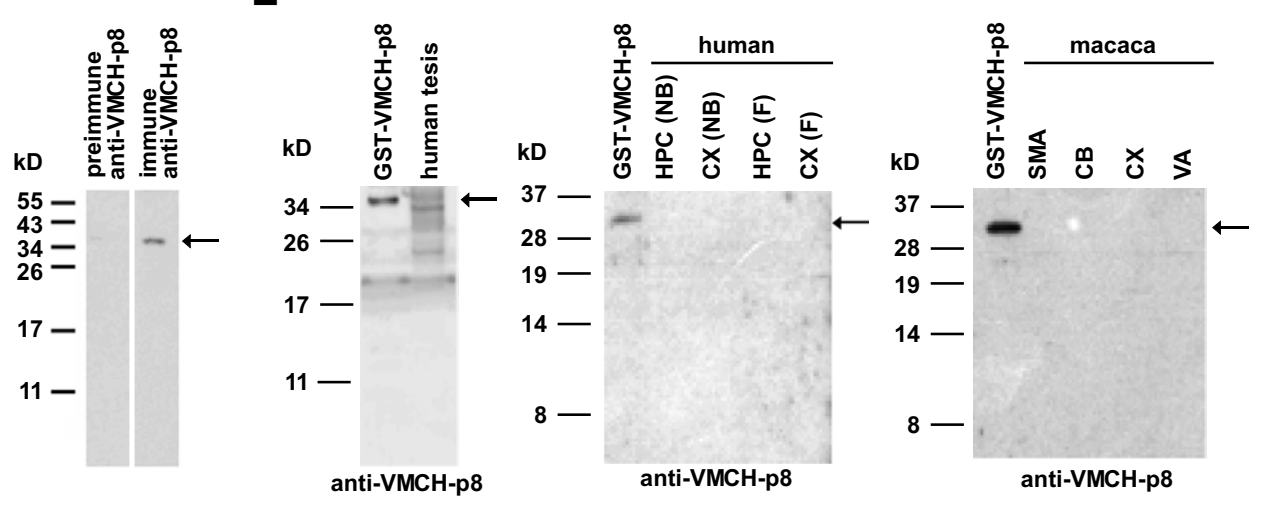

\section{Figure 6}

Analysis of the coding potential of VMCH-p8 and its variants in human and macaque tissues. (A) Schematic representation of PMCHL ORFI, encoding the putative VMCH-p8 protein, present on unspliced RNA, and its variants, ORFIa and ORFIb, present on spliced RNAs. (B) Sequence comparison of PMCHLI and PMCHL2 ORFI, ORFIa and ORFIb. The ORFI epitope is underlined. The putative nuclear localisation signal (NLS) is shaded in grey. The variable C-terminal parts are boxed. (C) Sequence comparisons of PMCHLI ORFI, ORFIa and ORFIb in Homo sapiens (HSA), Pan troglodytes (PTR), Pongo pygmaeus (PPY) and Macaca fascicularis (MFA). The variable C-terminal parts are boxed. (D) Specificity of the anti-VMCH-p8 antiserum. In Western blots, immune anti-VMCH-p8 serum detects the recombinant GST-VMCH-p8 protein (I2.5 ng) migrating at $34 \mathrm{kD}$ (arrow). (E) Western blot analysis of the expression of $\mathrm{VMCH}$-p8 and its variants in vivo in human and macaque tissues. GSTVMCH-p8 (I2.5 ng), human adult testis proteins (25 $\mu \mathrm{g})$, new-born (NB) and fetal (F) hippocampus (HPC) and prefrontal cortex proteins (CX) (80 $\mu \mathrm{g}$ each), and macaque supplementary motor area (SMA), cerebellum (CB), prefrontal cortex (CX) and visual area (VA) proteins ( $80 \mu \mathrm{g}$ each) were analysed using the anti-VMCH-p8 antiserum. The arrow points to GST-VMCH-p8 migrating at $34 \mathrm{kD}$. 
used in previous studies [28]. Other genomic samples were kindly provided by San Diego Zoo/CRES (Pan paniscus, Gorilla g.g., Pongo pygmaeus, Pongo p.abelii, Hylobates lar, Macaca silenus) and by Prof A. Blancher (Rangueil Hospital, Toulouse, France) (Cebus appella, Pan troglodytes). Genomic DNA was isolated from the occipital cortex of a Macaca fascicularis (provided by Dr. E. Bezard (Biothèque Primate/Primatech, CNRS, Bordeaux, France) according to the Blin and Stafford's method [66].

\section{RNA extraction and reverse-transcription}

Total RNAs were extracted from human and macaque tissues according to standard guanidium phenol method [67] and using a FastPrep apparatus (FP220A Thermo instrument, Qbiogene, France). Contaminating genomic DNA was removed from RNA preparation by RQ1 RNasefree DNase treatment (Promega) according to the manufacturer's protocol. cDNAs were synthesized by reversetranscription (RT) of $2 \mu \mathrm{g}$ of total DNase-treated RNAs using the SuperScript TM II Reverse Transcriptase (Invitrogen) and oligo dT according to the manufacturer's protocol.

\section{PCR amplification}

Oligonucleotides (list provided in Table 1) were purchased from Eurogentec (Belgium).

For genomic DNA, 100-200 ng were PCR-amplified using the oligonucleotide couples indicated in Table 1 and the LA Taq polymerase (Takara) following the supplier's protocol. Thirty-five cycles of amplification were carried out as follows: $30 \mathrm{~s}$ at $94^{\circ} \mathrm{C}$ (denaturation), $30 \mathrm{~s}$ at annealing temperature (indicated in Table 1), 1 to $10 \mathrm{~min}$ at $72^{\circ} \mathrm{C}$ (extension). A final extension step of $7 \mathrm{~min}$ at $72^{\circ} \mathrm{C}$ was performed. PCR products were purified using the NucleoSpin kit (Machery Nagel) and sequenced.

For RT samples and Marathon cDNA libraries, $2 \mu \mathrm{l}$ were PCR-amplified using the indicated primer pairs and the HotMaster Taq DNA polymerase (Eppendorf) following the supplier's protocol. Thirty-eight cycles of amplification were carried out as follows: $30 \mathrm{~s}$ at $94^{\circ} \mathrm{C}$ (denaturation), $30 \mathrm{~s}$ at annealing temperature (indicated in Table 1), 2 min at $65^{\circ} \mathrm{C}$ (extension). A final extension step of 7 $\min$ at $72^{\circ} \mathrm{C}$ was performed. When necessary, nested PCR was performed with internal primers using $2 \mu \mathrm{l}$ of a 1:20 dilution of the first round products. PCR-amplified fragments were subcloned into the pGEM-T Easy vector (Promega) and transfected into TOP10 thermocompetent cells (Invitrogen) according to the manufacturer's instructions, followed by plasmid DNA preparation using a Qiaprep Spin Miniprep kit (Qiagen) and sequencing.

\section{Southern blotting}

PCR products obtained with primer pair 3-7/3-30 (thirty-five cycles) were electrophoresed on a $1 \%$ agarose gel containing ethidium bromide and were visualized under UV. The gel was then denatured $15 \mathrm{~min}$ in $500 \mathrm{mM}$ $\mathrm{NaOH}, 1.5 \mathrm{M} \mathrm{NaCl}$ solution, neutralized $15 \mathrm{~min}$ in 500 $\mathrm{mM}$ Tris, $1.5 \mathrm{M} \mathrm{NaCl}$, and soaked $5 \mathrm{~min}$ in $2 \times$ SCC solution (300 mM NaCl, $30 \mathrm{mM}$ sodium citrate). The DNA was transferred overnight as a gravity-dry blot onto a cellulose membrane (Biodyne B, Pall Corporation, FL, USA). The membrane was prehybridized for $4 \mathrm{~h}$ at $65^{\circ} \mathrm{C}$ in Church solution (500 $\mathrm{mM} \mathrm{Na}_{2} \mathrm{HPO}_{4}, \mathrm{pH} \mathrm{6.8,5 \%} \mathrm{SDS),}$ hybridized overnight at $65^{\circ} \mathrm{C}$ in fresh Church solution containing previously prepared ${ }^{32} \mathrm{P}$-labeled $\mathrm{PMCHL}$-specific probe 1 corresponding to the fragment amplified with primer pair $3-25 / 3-30$ (see Table 1) at $5.10^{5}$ dpm. $\mathrm{ml}^{-1}$. ${ }^{32} \mathrm{P}$-labeled probes were prepared using the Prime-a-gene labelling system (Promega) according to the manufacturer's protocol. After hybridization, the membrane was washed twice $15 \mathrm{~min}$ in $2 \times$ SSPE and twice 10 min in $1 \times$ SSPE. Hybridized radioactive probes were detected with a Fujifilm phosphoimager (FLA-5100).

\section{DNA sequencing and alignment}

Sequencing of PCR-amplified fragments was carried out on both DNA strands using the Ampli Taq Polymerase FS, the Big Dye Terminator 1.1 sequencing kit (Applera), and a ABI PRISM 3100 sequencer (Perkin Elmer). Sequences obtained from the public databases (EMBL/GenBank/ DDBJ) and fragments sequenced by PCR were aligned manually using SEAVIEW [68]. Species are: Homo sapiens (HSA), Pan paniscus (PPA), Pan troglodytes (PTR), Pongo pygmaeus (PPY), Hylobates lar (HLA), Macaca mulatta (MML), Macaca fascicularis (MFA), Cercopithecus hamlyni (CHA), Chlorocebus aethiops (CAE), Cebus capucinus (CCA), Cebus apella (CAP), Saginus oedipus (SOE), Tarsius syrichta (TSY).

\section{Phylogenetic analysis}

Phylogenetic dendrograms were reconstructed according to three different methods: Neighbour Joining (BIONJ), Maximum Likelihood (ML, using the Global option), and Maximum Parsimony (MP). For the Neighbour Joining (NJ) analysis, a distance matrix was calculated by DNADIST according to the Kimura two parameters correction. Bootstraps were done using 1,000 replications, BIONJ and Kimura two parameters correction. BIONJ was according to Gascuel [69], ML and MP were from PHYLIP (Phylogeny Inference Package, version 3.573c, distributed by J. Felsenstein, Department of Genetics, UW, Seattle, WA, USA). Phylogenetic analyses were done excluding domains that were not common to every sequence as well as low complexity domains that could not be properly aligned. The phylogenetic dendrograms were drawn using NJPLOT [70].

\section{Preparation of proteins}

Human and macaque tissues were homogenized in RIPA buffer $(20 \mathrm{mM}$ Tris HCl, pH 7.4, $150 \mathrm{mM} \mathrm{NaCl}, 1 \%$ NP- 
40, 0.5\% sodium deoxycholic acid, 0.1\% SDS, $2 \mathrm{mM}$ EDTA, protease inhibitor cocktail Complete (Roche)) using a FastPrep apparatus (FP220A Thermo instrument, Qbiogene, France), incubated on ice for $30 \mathrm{~min}$, and centrifuged at $20000 \times \mathrm{g}$ for $15 \mathrm{~min}$ at $4^{\circ} \mathrm{C}$. Proteins in the supernatants were quantitated using a commercial Bradford reagent (BioRad).

\section{Production of recombinant GST-VMCHp8 protein}

PMCHL1 ORF1 encoding the putative VMCH-p8 protein was sub-cloned into the BamH1/EcoR1 sites of the pGEX$3 \mathrm{X}$ vector, in frame with GST (Amersham Biosciences). The construct was used to transform thermocompetent Rosetta cells (Novagen) and the recombinant GSTVMCH-p8 protein was produced and purified using glutathione-sepharose (Amersham Biosciences) beads according to the manufacturer's instructions.

\section{Antibodies}

Polyclonal antibodies were raised against the putative VMCH-p8 protein encoded by PMCHL1 ORF1. A peptide comprising the thirteen $\mathrm{N}$-terminal amino acids of the sequence (MLSQKPKKKHNFL) was designed by Dr B. Cardinaud (IPMC, Valbonne, France), synthesized and coupled to keyhole limpet haemocyanin (KLH) before rabbit immunization (Genaxis, Nîmes, France). AntiVMCH-p8 antiserum was used at a final dilution of 1:1,000. Secondary HRP-coupled goat anti-rabbit antibodies (Jackson ImmunoResearch) were used at a $1: 10,000$ dilution.

\section{Western blotting}

Proteins were separated on $12 \%$ Tris-glycine or $16.5 \%$ Tris-tricine gels under reducing conditions and transferred to nitrocellulose membranes (Schleicher \& Schuell, Germany) using a wet tank transfer system (BioRad). Membranes were blocked $1 \mathrm{~h}$ in TBS-T (137 mM NaCl, $2.7 \mathrm{mM}$ $\mathrm{KCl}, 2.5 \mathrm{mM}$ Tris, $\mathrm{pH} 7.4,0.1 \%$ Tween-20) containing 5\% fetal calf serum, incubated for $2 \mathrm{~h}$ at room temperature with primary antibodies (1:1000 dilution), followed by 1 $\mathrm{h}$ incubation with secondary antibodies, and revealed with the SuperSignal West Pico (Pierce) chemiluminescence detection system.

\section{Authors' contributions}

SS participated in conceiving and discussing the study, carried out the sequence analysis of ORFs, performed part of the Western blot experiments, oversaw part of the RNA characterization, organized the data, produced the final figures, and wrote most part of the manuscript. FDT participated in conceiving and discussing the study, carried out the genomic DNA sequencing, initiated and carried out part of the characterization of spliced transcripts, provided the sequence data for phylogenetic analyses, produced the VMCH-p8 fusion protein, drafted the figures and helped drafting the manuscript. MJA completed the characterization of the spliced transcripts, performed the analysis of the exon/intron boundaries, and helped preparing the figures and submitting the sequences. ADA carried out the Southern blot experiments and part of the Western blot experiments. RC performed the phylogenetic analyses and appended discussions. JLN conceived and supervised the project, participated in the discussion, wrote part of the manuscript and provided the financial support through grant applications. All authors read and approved the final manuscript.

\section{Acknowledgements}

We thank very much Drs F. Presse and E. Lalli (IPMC, Valbonne, France) for helpful advice and critical reading of the manuscript. We are grateful to Dr B. Cardinaud (IPMC, Valbonne, France) for developing the anti-VMCHp8 antiserum, and $C$. Payré for excellent technical assistance. We are grateful to Dr A. Coquerel (CHU Rouen, France), Dr D. Jordan (Faculté de médecine, Lyon, France), Dr E. Bezard (Biothèque Primate/Primatech, CNRS, Bordeaux, France), the National Neurological Research Specimen Bank (Los Angeles, CA, USA) and the GIE Neuro-CEB (Hôpital de la PitiéSalpétrière, Paris, France) for generously providing human and macaque tissues. Genomic DNAs were kindly provided by Dr B. Dutrillaux (CNRS, Institut Curie, Paris, France), by Dr P. Dijan (CEREMOD, Meudon, France), by Prof A. Blancher (Hôpital Rangeuil, Toulouse, France) and by Dr L. Chemnick (San Diego Zoo/CRES, San Diego, Ca, USA). This work was supported by the Centre National de la Recherche Scientifique (CNRS programme OHLL 2002-2004; crédits exceptionnels Biothèque Primate), by a 6th FP EU STREPS/NEST (APES project $n^{\circ} 28594$ ), and by the Agence Nationale de la Recherche (ANR MNP-2008). SS is presently supported by the APES project. FDT was a recipient of a fellowship from the French Education Ministry (Allocation couplée MENRS/ENS). ADA and MJA were supported by the CNRS (crédits exceptionnels Biothèque Primate). MJA was also supported by the MJ Fox Foundation.

\section{References}

I. King MC, Wilson AC: Evolution at two levels in humans and chimpanzees. Science 1975, I88:107-16.

2. Bailey JA, Eichler EE: Primate segmental duplications: crucibles of evolution, diversity and disease. Nat Rev Genet 2006, 7:552-64.

3. Khaitovich P, Enard W, Lachmann M, Paabo S: Evolution of primate gene expression. Nat Rev Genet 2006, 7:693-702.

4. Sikela JM: The jewels of our genome: the search for the genomic changes underlying the evolutionarily unique capacities of the human brain. PLoS Genet 2006, 2:e80.

5. Clark AG, Glanowski S, Nielsen R, Thomas PD, Kejariwal A, Todd MA, Tanenbaum DM, Civello D, Lu F, Murphy B, et al.: Inferring nonneutral evolution from human-chimp-mouse orthologous gene trios. Science 2003, 302:1960-3.

6. Dorus S, Vallender EJ, Evans PD, Anderson JR, Gilbert SL, Mahowald M, Wyckoff GJ, Malcom CM, Lahn BT: Accelerated evolution of nervous system genes in the origin of Homo sapiens. Cell 2004, I I 9: 1027-40.

7. Shi $P$, Bakewell MA, Zhang J: Did brain-specific genes evolve faster in humans than in chimpanzees? Trends Genet 2006, 22:608-13.

8. Keightley PD, Lercher MJ, Eyre-Walker A: Evidence for widespread degradation of gene control regions in hominid genomes. PLOS Biol 2005, 3:e42.

9. Sandelin A, Carninci P, Lenhard B, Ponjavic J, Hayashizaki Y, Hume DA: Mammalian RNA polymerase II core promoters: insights from genome-wide studies. Nat Rev Genet 2007, 8:424-36. 
10. Taylor MS, Kai C, Kawai J, Carninci P, Hayashizaki Y, Semple CA: Heterotachy in mammalian promoter evolution. PLoS Genet 2006, 2:e30.

II. Britten RJ: Divergence between samples of chimpanzee and human DNA sequences is $\mathbf{5 \%}$, counting indels. Proc Natl Acad Sci USA 2002, 99: I 3633-5.

12. Britten RJ, Rowen L, Williams J, Cameron RA: Majority of divergence between closely related DNA samples is due to indels. Proc Natl Acad Sci USA 2003, I 00:466I-5.

13. Frazer KA, Chen X, Hinds DA, Pant PV, Patil N, Cox DR: Genomic DNA insertions and deletions occur frequently between humans and nonhuman primates. Genome Res 2003, | 3:34|-6.

14. Cooper GM, Nickerson DA, Eichler EE: Mutational and selective effects on copy-number variants in the human genome. Nat Genet 2007, 39:S22-9.

15. Khaitovich P, Muetzel B, She X, Lachmann M, Hellmann I, Dietzsch J, Steigele S, Do HH, Weiss G, Enard W, et al.: Regional patterns of gene expression in human and chimpanzee brains. Genome Res 2004, 14:1462-73

16. Hahn MW, Demuth JP, Han SG: Accelerated rate of gene gain and loss in primates. Genetics 2007, 177:1941-9.

17. Stranger BE, Forrest MS, Dunning M, Ingle CE, Beazley C, Thorne N, Redon R, Bird CP, de Grassi A, Lee $C$, et al:: Relative impact of nucleotide and copy number variation on gene expression phenotypes. Science 2007, 3 I 5:848-53.

18. Sebat J: Major changes in our DNA lead to major changes in our thinking. Nat Genet 2007, 39:S3-5.

19. Courseaux A, Nahon JL: Birth of two chimeric genes in the Hominidae lineage. Science 200I, 291:1293-7.

20. Courseaux A, Richard F, Grosgeorge J, Ortola C, Viale A, Turc-Care C, Dutrillaux B, Gaudray P, Nahon JL: Segmental duplications in euchromatic regions of human chromosome 5: a source of evolutionary instability and transcriptional innovation. Genome Res 2003, 13:369-8I.

21. Nahon JL: Birth of 'human-specific' genes during primate evolution. Genetica 2003, I I 8:193-208.

22. Long M: Evolution of novel genes. Curr Opin Genet Dev 200I, I I:673-80.

23. Long M, Betran E, Thornton K, Wang W: The origin of new genes: glimpses from the young and old. Nat Rev Genet 2003, 4:865-75

24. Lee Y, Ise T, Ha D, Saint Fleur A, Hahn Y, Liu XF, Nagata S, Lee B, Bera TK, Pastan I: Evolution and expression of chimeric POTEactin genes in the human genome. Proc Natl Acad Sci USA 2006, I 03: 1 7885-90.

25. Burki $\mathrm{F}$, Kaessmann $\mathrm{H}$ : Birth and adaptive evolution of a hominoid gene that supports high neurotransmitter flux. Nat Genet 2004, 36: 1061-3.

26. Long M, Deutsch M, Wang W, Betran E, Brunet FG, Zhang J: Origin of new genes: evidence from experimental and computational analyses. Genetica 2003, I | 8: 17|-82

27. Viale A, Courseaux A, Presse F, Ortola C, Breton C, Jordan D, Nahon $\mathrm{JL}$ : Structure and expression of the variant melanin-concentrating hormone genes: only PMCHLI is transcribed in the developing human brain and encodes a putative protein. Mol Biol Evol 2000, I 7: 1626-40

28. Viale A, Ortola C, Richard F, Vernier P, Presse F, Schilling S, Dutrillaux $B$, Nahon JL: Emergence of a brain-expressed variant melaninconcentrating hormone gene during higher primate evolution: a gene "in search of a function". Mol Biol Evol 1998 , I5:196-214.

29. Schmidt EE: Transcriptional promiscuity in testes. Curr Biol 1996, 6:768-9.

30. Kleene KC, Mulligan E, Steiger D, Donohue K, Mastrangelo MA: The mouse gene encoding the testis-specific isoform of $\operatorname{Poly}(A)$ binding protein ( $\mathrm{Pabp} 2$ ) is an expressed retroposon: intimations that gene expression in spermatogenic cells facilitates the creation of new genes. I Mol Evol 1998, 47:275-8I.

31. Vinckenbosch N, Dupanloup I, Kaessmann H: Evolutionary fate of retroposed gene copies in the human genome. Proc Natl Acad Sci USA 2006, 103:3220-5.

32. Paulding CA, Ruvolo M, Haber DA: The Tre2 (USP6) oncogene is a hominoid-specific gene. Proc Natl Acad Sci USA 2003, I 00:2507-II.

33. Sorek R: The birth of new exons: mechanisms and evolutionary consequences. Rna 2007, I3:1603-8.
34. Akiva P, Toporik A, Edelheit S, Peretz Y, Diber A, Shemesh R, Novik $A$, Sorek R: Transcription-mediated gene fusion in the human genome. Genome Res 2006, I6:30-6.

35. Enard W, Paabo S: Comparative primate genomics. Annu Rev Genomics Hum Genet 2004, 5:351-78.

36. Glazko GV, Nei M: Estimation of divergence times for major lineages of primate species. Mol Biol Evol 2003, 20:424-34.

37. Patterson N, Richter DJ, Gnerre S, Lander ES, Reich D: Genetic evidence for complex speciation of humans and chimpanzees. Nature 2006, 44 I: I I03-8.

38. Wakeley J: Complex speciation of humans and chimpanzees. Nature 2008, 452:E3-4. discussion E4

39. Wall JD: Estimating ancestral population sizes and divergence times. Genetics 2003, 163:395-404.

40. Goodman M: The genomic record of Humankind's evolutionary roots. Am J Hum Genet 1999, 64:31-9.

41. Wildman DE, Uddin M, Liu G, Grossman LI, Goodman M: Implications of natural selection in shaping $\mathbf{9 9 . 4 \%}$ nonsynonymous DNA identity between humans and chimpanzees: enlarging genus Homo. Proc Natl Acad Sci USA 2003, 100:7181-8.

42. Altschul SF, Gish W, Miller W, Myers EW, Lipman DJ: Basic local alignment search tool. J Mol Biol 1990, 2I 5:403- I0.

43. Samonte RV, Eichler EE: Segmental duplications and the evolution of the primate genome. Nat Rev Genet 2002, 3:65-72.

44. Jurka J, Kohany O, Pavlicek A, Kapitonov VV, Jurka MV: Duplication, coclustering, and selection of human Alu retrotransposons. Proc Natl Acad Sci USA 2004, I 0 I : I 268-72.

45. Eichler EE, Johnson ME, Alkan C, Tuzun E, Sahinalp C, Misceo D, Archidiacono $N$, Rocchi $M$ : Divergent origins and concerted expansion of two segmental duplications on chromosome 16. I Hered 2001, 92:462-8.

46. Johnson ME, Cheng Z, Morrison VA, Scherer S, Ventura M, Gibbs RA, Green ED, Eichler EE: Recurrent duplication-driven transposition of DNA during hominoid evolution. Proc Natl Acad Sci USA 2006, 103:|7626-3|.

47. She X, Liu G, Ventura M, Zhao S, Misceo D, Roberto R, Cardone MF, Rocchi M, Green ED, Archidiacano N, et al: A preliminary comparative analysis of primate segmental duplications shows elevated substitution rates and a great-ape expansion of intrachromosomal duplications. Genome Res 2006, 16:576-83.

48. Basu S, Schaefer TM, Ghosh M, Fuller CL, Reinhart TA: Molecular cloning and sequencing of 25 different rhesus macaque chemokine cDNAs reveals evolutionary conservation among C, CC, CXC, AND CX3C families of chemokines. Cytokine 2002, 18:140-8.

49. Luenser K, Ludwig A: Variability and evolution of bovine betadefensin genes. Genes Immun 2005, 6: II 15-22.

50. Frith MC, Forrest AR, Nourbakhsh E, Pang KC, Kai C, Kawai J, Carninci P, Hayashizaki Y, Bailey TL, Grimmond SM: The abundance of short proteins in the mammalian proteome. PLoS Genet 2006, 2:e52.

5I. Clamp M, Fry B, Kamal M, Xie X, Cuff J, Lin MF, Kellis M, LindbladToh K, Lander ES: Distinguishing protein-coding and noncoding genes in the human genome. Proc Natl Acad Sci USA 2007 104: $19428-33$.

52. Kozak M: Compilation and analysis of sequences upstream from the translational start site in eukaryotic mRNAs. Nucleic Acids Res 1984, I 2:857-72.

53. Kawaji H, Nakamura M, Takahashi Y, Sandelin A, Katayama S, Fukuda S, Daub CO, Kai C, Kawai J, Yasuda J, et al.: Hidden layers of human small RNAs. BMC Genomics 2008, 9: 157

54. Mattick JS, Makunin IV: Non-coding RNA. Hum Mol Genet 2006, I 5(Spec No I): R I 7-29.

55. Storz G: An expanding universe of noncoding RNAs. Science 2002, 296: $1260-3$.

56. He S, Liu C, Skogerbo G, Zhao H, Wang J, Liu T, Bai B, Zhao Y, Chen R: NONCODE v2.0: decoding the non-coding. Nucleic Acids Res 2008, 36:DI70-2

57. Johnston CM, Nesterova TB, Formstone EJ, Newall AE, Duthie SM, Sheardown SA, Brockdorff N: Developmentally regulated Xist promoter switch mediates initiation of $x$ inactivation. Cell 1998, 94:809-17.

58. Panning B, Dausman J, Jaenisch $\mathrm{R}$ : $\mathbf{X}$ chromosome inactivation is mediated by Xist RNA stabilization. Cell 1997, 90:907-16. 
59. Sleutels F, Zwart R, Barlow DP: The non-coding Air RNA is required for silencing autosomal imprinted genes. Nature 2002, 4I5:810-3.

60. Kim M, Patel B, Schroeder KE, Raza A, Dejong J: Organization and transcriptional output of a novel mRNA-like piRNA gene (mpiR) located on mouse chromosome 10. Rna 2008, 14:1005-II.

61. Raho G, Barone V, Rossi D, Philipson L, Sorrentino V: The gas 5 gene shows four alternative splicing patterns without coding for a protein. Gene 2000, 256:13-7.

62. Tycowski KT, Shu MD, Steitz JA: A mammalian gene with introns instead of exons generating stable RNA products. Nature 1996, 379:464-6.

63. Lottin S, Vercoutter-Edouart AS, Adriaenssens E, Czeszak X, Lemoine J, Roudbaraki M, Coll J, Hondermarck H, Dugimont T, Curgy Jj: Thioredoxin post-transcriptional regulation by $\mathrm{HI} 9$ provides a new function to mRNA-like non-coding RNA. Oncogene 2002, $21:|625-3|$.

64. Szell M, Bata-Csorgo Z, Kemeny L: The enigmatic world of mRNA-like ncRNAs: their role in human evolution and in human diseases. Semin Cancer Biol 2008, 18:14|-8.

65. Matera AG, Terns RM, Terns MP: Non-coding RNAs: lessons from the small nuclear and small nucleolar RNAs. Nat Rev Mol Cell Biol 2007, 8:209-20.

66. Blin N, Stafford DW: A general method for isolation of high molecular weight DNA from eukaryotes. Nucleic Acids Res 1976, 3:2303-8.

67. Chomczynski P, Sacchi N: Single-step method of RNA isolation by acid guanidinium thiocyanate-phenol-chloroform extraction. Anal Biochem 1987, 162:156-9.

68. Galtier N, Gouy M, Gautier C: SEAVIEW and PHYLO WIN: two graphic tools for sequence alignment and molecular phylogeny. Comput Appl Biosci 1996, I 2:543-8.

69. Gascuel O: BIONJ: an improved version of the $\mathrm{NJ}$ algorithm based on a simple model of sequence data. Mol Biol Evol 1997, I 4:685-95.

70. Perriere G, Gouy M: WWW-query: an on-line retrieval system for biological sequence banks. Biochimie 1996, 78:364-9.
Publish with Bio Med Central and every scientist can read your work free of charge

"BioMed Central will be the most significant development for disseminating the results of biomedical research in our lifetime. "

Sir Paul Nurse, Cancer Research UK

Your research papers will be:

- available free of charge to the entire biomedical community

- peer reviewed and published immediately upon acceptance

- cited in PubMed and archived on PubMed Central

- yours - you keep the copyright
BioMedcentral 